\title{
The Omagh Bombing - A Medical Perspective
}

\author{
Capt SJO Potter \\ BSc (Hons), MB, ChB, RAMC \\ $\mathrm{RMO}$
}

4 Royal Irish Regiment, BFPO 804

\section{Dr GE Carter}

$\mathrm{MB}, \mathrm{ChB}, \mathrm{DRCOG}$

\section{GP Trainee}

SUMMARY: The bomb in Omagh on the 15th August 1998 was responsible for the largest loss of life of any single terrorist incident in the whole of the "Troubles" in Northern Ireland. However, the medical response to this tragedy provided an excellent opportunity for the civilian and military agencies to work together. As a consequence of this a number of lessons were drawn which are presented in the paper. Whatever the outcome of the peace process these lessons will have an important role in the future, since history would suggest that there is little possibility of the terrorist threat ever completely receding.

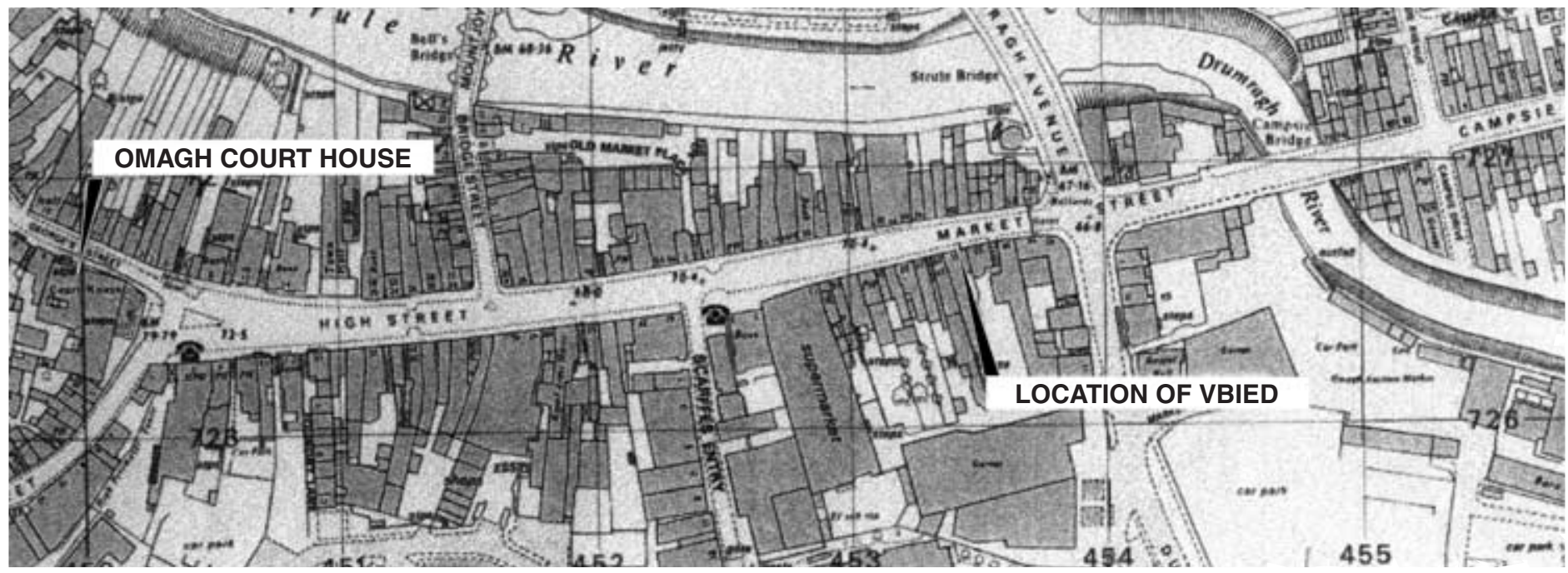

Fig 1. Diagram showing location of Court House in relation to actual location of car bomb. (VBIED)

The Good Friday Agreement heralded a new era for the people of Northern Ireland. It was with great belief in the Ulster Referendum that they dared to look forward to peace. The Canary Wharf, Thiepval Barracks and Manchester bombings which all occured during previous PIRA cease-fires provided ample proof that negotiations could fail.

Unfortunately the cease-fire did not last. Militant members of PIRA were known to have defected to dissident terrorist groups. One such organisation, the Real IRA stepped up their campaign for recognition. On 01 August 1998 a car bomb was detonated in Banbridge High Street. Fortunately, although buildings were damaged no one was killed.

Two weeks later Omagh was targeted. Twenty nine people were killed and 336 were injured - the largest single loss of life in 30 years of urban war. The injured rapidly engulfed the local Accident and Emergency (A\&E) department and caused one of the largest ever UK casualty evacuations by road and air. The ensuing maelstrom severely tested acute medical services in Northern Ireland. This article discusses the immediate medical response to the Omagh bombing and offers advice to those who plan for such disasters.

\section{Background}

Omagh is a small Garrison town in West Tyrone situated 60 miles west of Belfast. The population is a roughly even mix of both Catholic and Protestant communities who are served by a small district general hospital - The Tyrone County. The Ballygawley Bus bombing in 1988 ( 8 dead) and the Teebane massacre in 1992 ( 8 dead) had been the previous largest atrocities in the area although there had also been many smaller shootings and bombings locally. The town though had been relatively spared except for the court-house which had been bombed on several occasions over the years.

August 15th was a childrens' carnival day in Omagh, people had descended on the town centre to shop or participate in the celebration. Many had travelled from the Republic of Ireland including a party of Spanish children. The town was also full of busy Saturday afternoon shoppers.

At 1430 a member of the Real IRA telephoned Ulster Television newsdesk from a callbox in Forkhill, South Armagh. The caller, who spoke in Gaelic, claimed that a bomb had been placed outside the courthouse in Omagh and would detonate soon. This message was then repeated to the Samaritans in Coleraine and once again to the Ulster Television Newsdesk. Each time the messages were in Gaelic and the timings and location were changed.

These messages were relayed to the police headquarters in Omagh. There was confusion over the exact location of the device. The area around the courthouse was cleared and the public were shepherded by the RUC to a first cordon line below a dip at the south end of the Market Street (Fig 1). The carnival atmosphere, the ensuing civilian lack of urgency - combined 


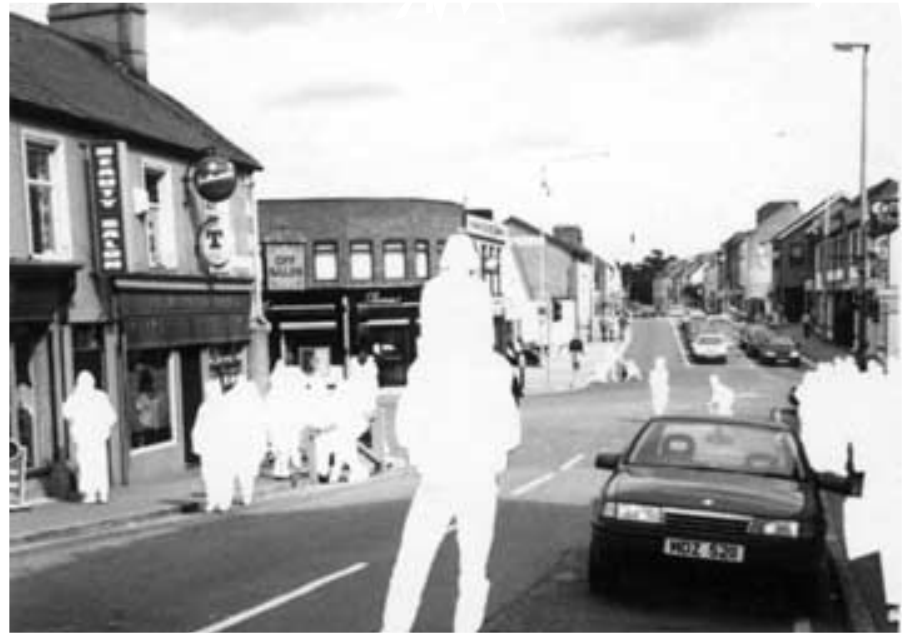

Fig 2.

with human curiosity, meant that many people were slow to progress to the next cordon line (350 metres from the court house) at Dublin Road. (A photograph taken by a fatally wounded Spaniard minutes before the bomb exploded showed many people who were killed by the bomb (Fig 2)).

A mauve Vauxhall Cavalier which had been stolen in the Irish Republic three days previously had been recorded entering Northern Ireland through South Armagh. It then proceeded to travel westwards to Omagh where it was parked sometime on Saturday outside No 31 (Kells) shop in Market Street. At 1510, the car which was filled with an estimated 250lbs of Home Made Explosive (HME) detonated (Fig 3).

\section{The Immediate Response}

The car disintegrated leaving a hole 3 feet deep in the road. Molten shrapnel from the car body was scattered up to 80 metres away in all directions. The accompanying blast wave killed and maimed in a direct line and as it rebounded between the high buildings which were approximately 25 metres apart. It is almost certain that 20 people died in that split second.

To add to the confusion the bomb had severed fibre optic communication cables buried beneath the street. As a result of the static caused by the bomb, mobile phones were inoperable and those that did work were soon unable to make calls due to the density of calls being made. The RUC station located $600 \mathrm{~m}$ away did not initially know the location of the device but clues were given by security firms in London who had called to say their alarms had been activated in Market Street.

The chaos was made worse by the choking dense smoke and spurting water-mains. Additionally, severed electrical cables provided more danger to the rescuers. The immediate response was that anyone who could help those around them did. The RUC, off duty soldiers and anyone with first aid experience organised those around them. First aid packs were removed from arriving police cars and people improvised using shop drapery to stem the blood loss. The heat of the metal cauterised many wounds in an instant - it was noted that there was less blood at the scene than expected.

The scale of casualties caused an unwitting but surprisingly accurate triage system to form. Those who appeared dead were left for dead and those who were conscious were given first aid and then moved in a chaotic priority system to the Tyrone County hospital. Bodies were put on planks, advertising hoardings and on sheets and lifted to Dublin Road. Any available vehicle was used to collect the injured. Buses, cars and taxis queued to receive the injured to take them to the A\&E department. Paramedics and later the Army medical team then entered the street to give assistance.

At Lisanelly barracks the decision was made that the RMO 1 Queens Lancashire Regiment (QLR) would set up the medical centre to receive patients. The RMO 4 R IRISH then deployed with ATO and C Company 1QLR to the scene. The team consisted of the RMO, med Sgt, a CMT 1 and an RMA driver. The indication at this time was that the bomb had exploded at the courthouse. The team were therefore surprised to find the location and the number of casualties at the scene.

ATO and the medics were wary of the possibility of a secondary device (with the Thiepval Barracks bombing in mind). A white Vauxhall Astra parked 20 metres up the road was an immediate source of worry but with many casualties evident an instant decision was made to enter the Street. The Medical team set about assessing those who were on the road and searched through the rubble and damaged buildings for survivors. Any trivial injuries were sent to the awaiting ambulances. Buildings containing casualties were still on fire with sparking electrical cables, water and falling masonry an ever present danger. Bodies were dragged into the street by medics, firemen and RUC and then assessed by the RMO - the only doctor present.

During the search an RMA found the camera containing the now infamous picture of the car. At one stage a woman was turned over by the RMO and medic to find a small child lying naked beneath her mother. This caused the emotional collapse of the soldier who was then removed from the scene. It was presumed that many of the civilian agencies might be related to the victims and so an effort was made to wrap and cover the remains from these rescuers.

After approximately 40 minutes it was realised that there were no other survivors present. The remains collected were gathered together in an alleyway and shop. Many of the victims showed little in the way of obvious trauma - and were assumed to be the victims of primary blast injury. Several though, were decapitated and suffered multiple traumatic amputations. Burns were common and shrapnel and glass injuries widespread. In a few cases only body parts were found. The RMO pronounced 21 dead at the scene (Fig 4).

It was notable that some bodies found 25 metres from the bomb had minimal external injury. It is presumed that the blast may have rebounded around the walls of the street as survivors standing next to these victims had only minimal physical injury. One woman standing 5 metres in front of the car survived untouched except for her shopping which was blown away leaving only the plastic grips in her hands.

The victims were then transferred to the bubble gym at

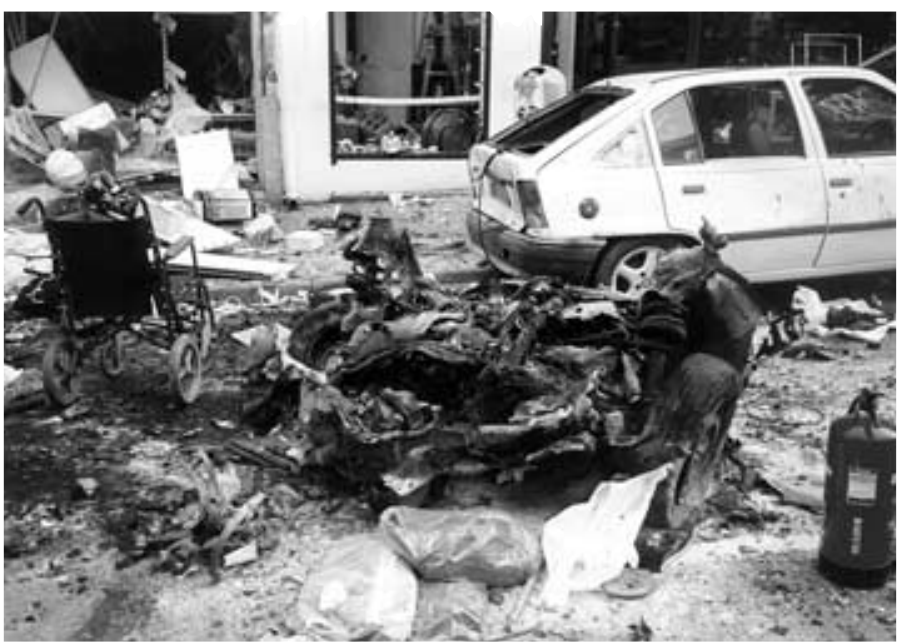

Fig 3. 


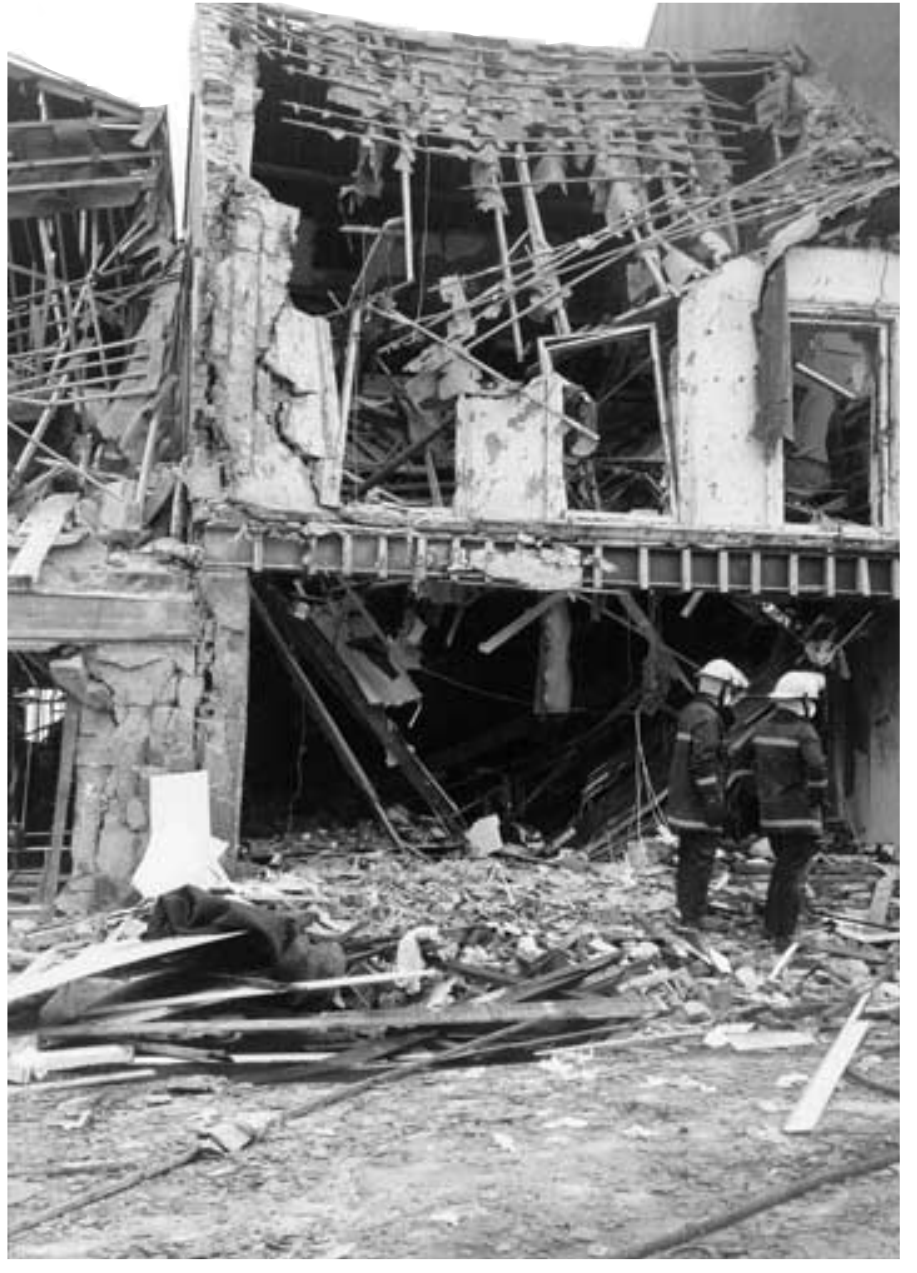

Fig 4.

Lisanelly Barracks. The Northern Ireland Body recovery team had been alerted. The Cricket pavilion was converted into a reception and viewing room using flowers from the 1 QLR Ball which was due to be held that evening.

\section{The Hospital Response}

The Tyrone County Hospital is a small DGH located three quarters of a mile from Market Street. As with all hospitals at this time of year it had received a new influx of junior doctors. On 10th August 1998 the hospital had practised its Major Incident Plan in response to a simulated major road traffic accident. In the debrief one fortunate observation was that a senior Board Member had parked his car on the Helipad.

At 1530 on 15th August the staffing cover was minimal as it was a weekend. No consultants were present. On hearing the bomb the senior sister initiated the Major Incident Plan. All emergency staff were contacted but before many had mustered the injured began to arrive. When the scale of the disaster was realised, local television broadcast a request for all medical and nursing volunteers to attend. Westdoc, the co-operative for local GPs was also alerted.

The small A\&E department soon became overwhelmed as junior medical staff attempted to treat the most seriously injured. As the deluge of patients continued, triage nurses began categorising their injuries and prioritising treatment. Soon, the 50 Emergency Casualty cards were depleted. If resuscitation was unsuccessful bodies were placed under trolleys to save space.

The sheer volume of casualties, relatives and media soon choked the entrances, corridors and wards. The senior medical staff began triage and urgent surgery was commenced. A surgeon from Dungannon travelled to help the only consultant surgeon present. Staff and patients were allocated to wards and were regularly retriaged. Major and minor treatment areas were opened. With the numbers of volunteers involved there was concern that bogus medical or nursing staff could be present. Few had any identification or could confirm their status so only staff recognised by key personnel were allowed to assist in the major treatment areas. There were no identification vests available for the use of volunteer staff.

The telephone system in the hospital was saturated by worried families and media interest. This meant that key clinical staff, laboratories, theatres etc. could not be contacted. Communication with referral hospitals also proved troublesome but tie-lines were extremely valuable. Land-lines were damaged therefore protected telephone numbers were not released by the RUC. The use of clerks acting as runners and information gatherers proved hopeless as they were repeatedly stopped by the crowds in the corridors as were the people sent to find them. Media reports that blood donation was urgently required were initially unfounded and switchboards were blocked by donors ringing hospitals throughout Northern Ireland.

When it was found that there were only five patients who needed treatment at Lisanelly medical centre RMO 1 QLR went to Market Street - neither medical officer had a radio so a face to face action plan was required. It was determined that the site was too dangerous for both doctors so RMO 1 QLR was dispatched to the hospital. In A\&E he was joined by two doctors - wives of officers from the camp who had seen the television appeal. With the arrival of more staff, patients were triaged at each entrance by a doctor and nurse and then retriaged after treatment. It became evident that the efficiency of the hospital depended on people control and communication. The Hospital was overwhelmed (Table 1) and therefore patients had to be evacuated urgently to peripheral and tertiary units around Northern Ireland (Table 2).

Table 1

Patients seen on 15th August 1998 at Hospital in Northern Ireland

\begin{tabular}{|lc}
\hline A \& E Attendance's 336 on day : 46 day after \\
Admissions on day & 129 \\
Abdo organ injuries & 4 \\
Amputations & 5 \\
Blast Lung & 1 \\
Burns & 8 \\
Eye injuries & 2 \\
Fractures & 24 \\
Fracture \& eye injury & 3 \\
Head injury & 1 \\
Soft Tissue Injury & 10 \\
Shrapnel Wounds & 72
\end{tabular}

Table 2

Hospitals Receiving Casualties on 15th August 1998

\begin{tabular}{|lcc|}
\hline Hospital & $\begin{array}{c}\text { Number } \\
\text { Attended }\end{array}$ & $\begin{array}{l}\text { Number } \\
\text { Admitted }\end{array}$ \\
\hline Tyrone County & 209 & 69 \\
Erne, Enniskillen & 71 & 39 \\
Altnagelvin & 30 & 10 \\
South Tyrone, Dungannon & 26 & 11 \\
Total & $\mathbf{3 3 6}$ & $\mathbf{1 2 9}$ \\
\hline
\end{tabular}

NB. A number of patients were recorded as attending more than one A \& E department on 15th August 1998.

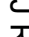

\section{定}

\section{엉}




\section{The evacuation of casualties}

Ambulances from all over the Western stations in Northern Ireland were summoned to assist with casualty transfer. This evacuation was reinforced using helicopters from Lisanelly Barracks, Aldergrove and Grosvenor Barracks Enniskillen. There was little co-ordination at first, as to which patient travelled by which means. An audit carried out by Mr McKinney, A\&E Consultant at Altnagelvin Hospital indicated that helicopter transfer was not on all occasions used to transfer the most seriously wounded.

Throughout the day liaison between ambulances, military medics and operating theatres in prioritising patients was poor. Lack of communication and saturation of facilities by the injured meant that back door triage was carried out in the helicopter doorway by the RMOs. Control around the helicopters became easier when two RUC officers were appointed to police the helipad. Until then some patients attempted to bypass the A\&E department and enter the helicopters - hysterical relatives also demanded their families should have priority. For safety, all helicopters closed their engines down on landing.

No single person could control the evacuation. A QLR air liaison signaller and multiple were deployed to co-ordinate and protect helicopter movements. Helicopters circled above awaiting the next load. On several occasions the arrival of a helicopter was greeted by injured on trolleys complete with attendant staff and life support equipment - only to be told the patient was triaged by the RMO as less severe. On one occasion a patient was placed on board and secured only to be exchanged for another when he was deemed a higher triage category. These problems were exacerbated by a total lack of notes in several cases. Verbal description of the injuries proved inadequate due to the noise. RMOs had to strip and examine the casualties to establish the injuries sustained before take off and when airborne.

\section{Table 3}

\section{Summary of Helicopter Evacuation}

\section{4 helicopters used - Puma / Sea King}

36 very seriously injured patients transferred

9 return journeys in total to RVH/ Altnegelvin/Erne

The first helicopter landed at the Royal Victoria Hospital $(\mathrm{RVH})$ in Belfast only to be rudely advised by a security guard that it could not land in the car park. The Helicopter then had to land at Duke of Connaught Unit - Musgrave Park Hospital. The injured patients therefore spent 10 minutes in a military ambulance and received an RUC escort from Grosvenor Road police station back to the RVH.

With good resuscitation and stabilisation by both military and civilian staff - coupled with great piloting skill no patients died during the air casevac. Resuscitation equipment levels were soon depleted as they were not returned to Omagh. This meant that obsolete and inoperable equipment was placed on helicopters. On one occasion both suction and defibrillator monitoring equipment failed. At DCU, where necessary, patients were stabilised in resus before transfer to the RVH (one patient received bilateral chest drains and cut downs).

Ambulances transported the vast majority of patients to hospitals throughout the province. In many cases the receiving units had activated their major incident plan to cope with the numbers arriving. In one case a pedestrian was killed by an ambulance during a patient transfer.

\section{Identification of bodies}

The Body Recovery Team proceeded with their tasks as the dead arrived from Market Street and later Tyrone County Hospital. Those patients who had died in A\&E or in operating theatres and had been pronounced dead were certified by the RMOs. They both remained on site and accompanied families into the viewing room for body identification. 1 QLR soldiers who prepared the bodies in the mortuary were all of senior rank and all had served in Bosnia.

\section{The Aftermath}

All personnel from both battalions who were involved in the bombing were seen 3 days afterwards by the Critical Incident Stress Debriefing Team. There was a mixed reaction to its benefits but undoubtedly the process did help some individuals. Sessions were also organised for families who were in Market Street.

\section{Lessons Learned}

There were many lessons for all concerned after the bombing. The Hospital, RUC, medics and all other agencies who were integral to the follow up operations have their own potent messages. The areas of importance identified were:

1. Preparation - it is essential that appropriate preparation of personnel, equipment and major incident procedures is in place. A number of involved personnel commentated that prior exposure to similar injuries in a controlled environment would have reduced the traumatic effects of the day itself.

2. Communications - it was clear that the provision of adequate radio equipment is essential for medical efficiency.

3. Liaison with Local Hospitals - liaison with local hospitals should be established in order to define the role of the military in civilian major incident plans. Direct communication links between military and civilian agencies should be in place.

4. Staff identification - it became clear that the use of "personnel bibs" for staff identifications would make a major impact on the organisation of the medical response.

5. Control of all entrances and exits - all entrances and exits to medical areas should be robustly policed in order to allow only staff and patient entry.

6. Patient Identification - adequate triage / body silhouette cards should accompany the patients at all times in order to prevent re-examination and waste of valuable medical time.

7. Triage for Transport - the medical response must include the provision of appropriately trained personnel to take responsibility for triage for transport.

8. Helicopter familiarity - all military medics should be fully acquainted with helicopter handling and rigging for casualties.

9. Triage techniques - all medics should be familiar with the basic principles of triage.

10. Exchange equipment - receiving Hospitals should have resuscitation and monitoring equipment immediately ready to return with transport. This will prevent equipment depletion. In addition equipment should be compatible with helicopter systems.

\section{Acknowledgments}

We would like to thank the following people for their kind assistance in producing this paper. Mr Eugene Fee, Mrs Martina Corrigan of Sperrin and Lakeland Trust and Dr Clive Russell, Clinical Director, Sperrin and Lakeland Trust. 